\title{
Index System Predigesting of Equipment Support Command Effectiveness Assessment Based on Rough Set Theory
}

\author{
Yongfeng Ma ${ }^{1, \text { a }}$, Jianjiang Zhao ${ }^{2, \text { b }}$, Fengjun Qi ${ }^{1, \mathrm{c}}$, Xun Zhou ${ }^{1, \mathrm{~d}}$ \\ ${ }^{1}$ Changchun Vocational Institute of Technology, Changchun 130117, China \\ ${ }^{2}$ Bengbu college, Bengbu 233050, China \\ a36261028@qq.com, b149635786@qq, 'qifengjun@163.com, dzhouxun@163.com
}

\begin{abstract}
Aiming at numerous and overlap evaluation indexes of nowadays the index system of equipment support and command effectiveness assessment, the predilection method of the index system of equipment support and command effectiveness assessment based on rough set theory is explored, and the example to build the predigest index system of equipment support and command effectiveness assessment is analyzed, so as to provide basements for the analysis of equipment support and command effectiveness assessment.
\end{abstract}

Keywords: equipment support command; effectiveness evaluation; rough set theory; predilection.

\section{Introduction}

In the war of the informational condition, the function of the equipment support command upgrades incessantly, and the effective exerting of the equipment support command has influenced tremendously on the victory or defeat of the war. The analysis and evaluation on the effective of the equipment support command has become one important and pressing mission [1]. However, the index of the equipment support command is numerous, overlap, repeated and equivalent, which causes the solving of the evaluation model become difficulty, and the index system needs to be optimized. The rough set theory is adopted to reduce the index system of the equipment support command, and the optimizing method of the index system is built based the theory [2].

\section{The index system of equipment support command effectiveness assessment}

The establishing principles of the index system of the equipment support command effectiveness assessment are as follows:

\subsection{The principle of systematic character.}

The evaluation index system should reflect synthetically of the whole situation of the evaluation object, and form the systematic building project. The indexes are set based on the character and process of the equipment support command activities, and the main factors are grasped to make sure the comprehensiveness and reliability, which reflect the direct effect and the indirect effectiveness.

\subsection{The principle of independent character.}

The evaluation indexes of same administrative levels are independent and have no crossover. Generally speaking, the index system of the equipment support command effectiveness assessment is composed of multi administrative levels. The principle of independent character requires that two or multi indexes have no superposition and causal relationship, which make sure the veracity of the index system.

\subsection{The principle of operable character.}

The evaluation indexes must accord with the equipment support fact of the army; the steps, methods, computation must be scientific, external and easy to actualize.

The index system of the equipment support command effectiveness assessment is built as shown in the figure 1, which based on the mission and characteristic of the equipment support, combined of the main factors influencing the effectiveness. 


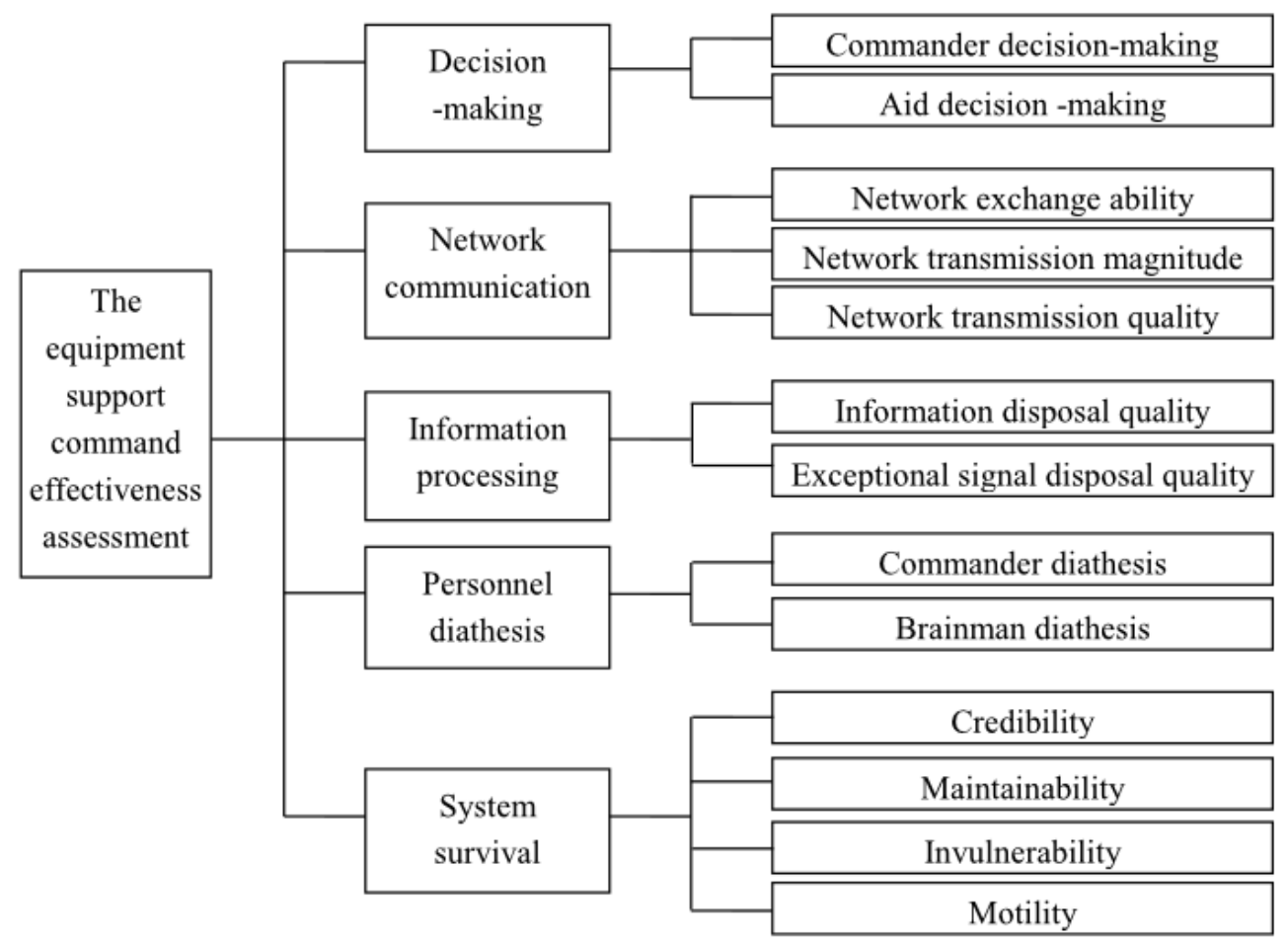

Figure 1 Index system of the equipment support command effectiveness

\section{The simplification of the index system based on rough set}

The rough set, which is the math theory of dealing with the imprecise, uncertain and incomplete data, is brought forward by the Poland mathematician Z.Pawlak in 1982. At present, obtaining of high-performance predilection method is one of the main problems the theory researches. The attribute predilection researches mainly whether each equivalent relationship is necessary or not in the approximate space, and how to delete the unnecessary knowledge. In the system effectiveness assessment, the attributes are not of the same importance, and some attributes of those even are redundant. The knowledge predilection means to delete the unconcerned and unimportant attributes in the condition of make sure the ability of the information system is invariant [3].

Order $\mathrm{R}$ as a group of the equivalence relation, $P \in R$, if $\operatorname{ind}(R)=\operatorname{ind}(R-\{P\}), \mathrm{P}$ is unnecessary in R. Contrarily, $\mathrm{P}$ is necessary in R. If each $P \in R$ is necessary in the $\mathrm{R}, \mathrm{R}$ is unattached. Contrarily, $\mathrm{R}$ is reliant. Suppose $P \subseteq R$, if $\mathrm{P}$ is unattached, and $\operatorname{ind}(\mathrm{P})=\operatorname{ind}(R), \mathrm{P}$ is a reduction of $\mathrm{R}$. When $\mathrm{R}$ has several reductions, the set composed by all the necessary relation is the core of R., which is note $\mathrm{d}$ as core $(\mathrm{R})$.

Theorem 1: $\operatorname{Core}(R)=\cap \operatorname{red}(R), \operatorname{red}(R)$ express all the reductions of $\mathrm{R}$. In the applications, the relationship of the different class is very important especially in the decision-making tables. So the concept of the relative reductions and relative core is introduced.

Order $\mathrm{P}$ and $\mathrm{Q}$ are the equivalence relation of $\mathrm{U}$, the positive field of $\mathrm{Q}$ is noted as $\mathrm{Pos} p(Q)$, $\operatorname{Pos}_{p}(Q)=\underset{x \in U / Q}{\mathrm{U}} P(X)$.

The positive field $\mathrm{P}$ of $\mathrm{Q}$ is the object set which can be partitioned to the equivalence kind of the relation $\mathrm{P}$ based the $\mathrm{U} / \mathrm{P}$ information of $\mathrm{U}$.

Order the $\mathrm{P}$ and $\mathrm{Q}$ are the equivalence relation, $\mathrm{R} \in \mathrm{P}$. if $\operatorname{Pos}_{P}(Q)=\operatorname{Pos}_{P-R}(Q), \mathrm{R}$ is $\mathrm{Q}$ unnecessary of $\mathrm{P}$. If every $\mathrm{R}$ is $\mathrm{Q}$ necessary in $\mathrm{P}, \mathrm{P}$ is called $\mathrm{Q}$ unattached. When $\mathrm{P}-\mathrm{R}$ is the $\mathrm{Q}$ unattached subfamily, and $\operatorname{Pos}_{P}(Q)=\operatorname{Pos}_{P-R}(Q), \mathrm{P}-\mathrm{R}$ is called $\mathrm{Q}$ relative predilection. All $\mathrm{Q}$ of $\mathrm{P}$ is the intersection of the relative predilection set, is called $\mathrm{Q}$ relative core of $\mathrm{P}$, which is noted as Core $_{Q}(P)$.

The relationship between the relative core and relative predilection is shown in the theorem 2 . 
Theorem 2: Core $_{Q}(P)=\cap \operatorname{red}_{Q}(P), \operatorname{red}_{Q}(P)$ is the set composed of Q predigesting of all $\mathrm{P}$ in the formula.

This paper aims to analyze the predilection of the 5 class one indexes. Table 1 shows the scores of the 5 class one indexes(command and decision-making, network communication, information processing, personnel diathesis, system survival) which marked by 12 experts. The five-grade marking system is adopted in the marking. 1 point represents unimportant, 2 points represent not very important, 3 points represent important, 4 points represent more important, 5 points represents very important. $\alpha_{1}, \alpha_{2}, \alpha_{3}, \alpha_{4}, \alpha_{5}$ represent the 5 indexes including command and decision-making, network communication, information processing, personnel diathesis and system survival.

Table 1 The decision-making table of equipment support command effectiveness assessment

\begin{tabular}{|c|c|c|c|c|c|c|}
\hline \multirow{2}{*}{ domain } & \multicolumn{7}{|c|}{ The condition attribute } & \multirow{2}{*}{ The decision-making attribute } \\
\cline { 2 - 6 } & $\alpha_{1}$ & $\alpha_{2}$ & $\alpha_{3}$ & $\alpha_{4}$ & $\alpha_{5}$ & 4 \\
\hline 1 & 4 & 2 & 4 & 3 & 4 & 3 \\
\hline 2 & 3 & 3 & 1 & 3 & 3 & 4 \\
\hline 3 & 4 & 3 & 4 & 2 & 4 & 3 \\
\hline 4 & 5 & 2 & 4 & 3 & 4 & 3 \\
\hline 5 & 4 & 1 & 4 & 1 & 4 & 4 \\
\hline 6 & 5 & 2 & 1 & 4 & 5 & 4 \\
\hline 7 & 5 & 5 & 3 & 4 & 5 & 3 \\
\hline 8 & 3 & 5 & 1 & 3 & 3 & 3 \\
\hline 9 & 5 & 2 & 3 & 4 & 5 & 4 \\
\hline 10 & 1 & 3 & 4 & 2 & 1 & 3 \\
\hline 11 & 3 & 5 & 2 & 1 & 3 & 4 \\
\hline 12 & 1 & 3 & 4 & 5 & 4 & \\
\hline
\end{tabular}

3.1 Validating whether each index is necessary to the decision-making attribute

ind $(C)=\{\{1\},\{2\},\{3\},\{4\},\{5\},\{6\},\{7\},\{8\},\{9\},\{10\},\{11\},\{12\}\}$

$\operatorname{ind}(D)=\{\{1,3,6,7,10,11\},\{2,4,5,8,9,10,12\}\}$

$\operatorname{pos}_{C}(D)=\underset{\forall x \in \text { ind }(D)}{U} \underline{C}(D)=\{1,2,3,4,5,6,7,8,9,10,11,12\}=U$

So the decision-making table is consistent.

$\alpha_{1}, \alpha_{2}, \alpha_{3}, \alpha_{4}, \alpha_{5}$ is deleted respectively to the condition attribute, it is known that:

ind $\left(C-\left\{\alpha_{1}\right\}\right)=\{\{1,4\},\{2\},\{3\},\{5\},\{6\},\{7\},\{8\},\{9\},\{10\},\{11\},\{12\}\}$

ind $\left(C-\left\{\alpha_{2}\right\}\right)=\{\{1\},\{2,8\},\{3\},\{4\},\{5\},\{6\},\{7,9\},\{10\},\{11\},\{12\}\}$

$\operatorname{ind}\left(C-\left\{\alpha_{3}\right\}\right)=\{\{1\},\{2\},\{3\},\{4\},\{5\},\{6,9\},\{7\},\{8\},\{10\},\{11\},\{12\}\}$

$\operatorname{ind}\left(C-\left\{\alpha_{4}\right\}\right)=\{\{1\},\{2\},\{3\},\{4\},\{5\},\{6\},\{7\},\{8\},\{9\},\{10\},\{11\},\{12\}\}$

ind $\left(C-\left\{\alpha_{5}\right\}\right)=\{\{1\},\{2\},\{3\},\{4\},\{5\},\{6\},\{7\},\{8\},\{9\},\{10\},\{11\},\{12\}\}$

So: $\operatorname{pos}_{C-\{\alpha 1\}}(D) \neq \operatorname{pos}_{C}(D) \quad \operatorname{pos}_{C-\{\alpha 2\}}(D) \neq \operatorname{pos}_{C}(D)$

$\operatorname{pos}_{C-\{\alpha 3\}}(D) \neq \operatorname{pos}_{C}(D) \quad \operatorname{pos}_{C-\{\alpha 4\}}(D)=\operatorname{pos}_{C}(D)$

$\operatorname{pos}_{C-\{\alpha 5\}}(D)=\operatorname{pos}_{C}(D)$

So, $\alpha_{1}, \alpha_{2}$ and $\alpha_{3}$ is necessary relative to $\mathrm{D}$ in $\mathrm{C}, \alpha_{4}$ and $\alpha_{5}$ is unnecessary relative to $\mathrm{D}$ in $\mathrm{C}$. Apparently, the relative D core of the decision-making table core $_{C}(D)=\left\{\alpha_{1}, \alpha_{2}, \alpha_{3}\right\}$.

\subsection{Validating whether each subfamily set is independent to the decision-making attribute}

The discretional relative predilection in the decision-making table is infinitesimal attribute subfamily set to keep the classifying ability constantly, which must contain relative D core, because deleting discretional factor in the relative core will change and weaken the classifying ability of the decision-making table. To obtain the relative predilection of decision-making table, $\alpha_{1}$, $\alpha_{2}$ and $\alpha_{3}$ attribute is necessary absolutely, while $\alpha_{4}$ and $\alpha_{5}$ attribute is unnecessary, but cannot be 
omitted synchronously. So these 3 double combination need to be considered to obtain all the predilection situation of the decision-making attribute.

$$
\begin{aligned}
& P_{1}=\left\{\alpha_{1}, \alpha_{2}, \alpha_{3}\right\} \\
& P_{2}=\left\{\alpha_{1}, \alpha_{2}, \alpha_{3}, \alpha_{5}\right\} \\
& P_{3}=\left\{\alpha_{1}, \alpha_{2}, \alpha_{3}, \alpha_{4}\right\}
\end{aligned}
$$

To the attribute subfamily set $P_{1}=\left\{\alpha_{1}, \alpha_{2}, \alpha_{3}\right\}$, it is of relative independence to $\mathrm{D}$ obviously. Because:

$$
\operatorname{ind}\left(P_{1}\right)=\{\{1\},\{2\},\{3\},\{4\},\{5\},\{6\},\{7\},\{8\},\{9\},\{10,12\},\{11\}\}
$$

So: $\operatorname{pos}_{P 1}(D)=\{1,2,3,4,5,6,7,8,9,11\} \neq \operatorname{pos}_{C}(D)$. So $P_{1}$ is not satisfied of the relative predilection theorem, which show that $P_{1}$ isn't the D predilection of the decision-making.

To the attribute subfamily set $\mathrm{P}_{2}=\left\{\begin{array}{lll}\alpha_{1}, & \alpha_{2}, \alpha_{3}, \alpha_{5}\end{array}\right\}$, because:

$\operatorname{ind}\left(P_{2}\right)=\{\{1\},\{2\},\{3\},\{4\},\{5\},\{6\},\{7\},\{8\},\{9\},\{10\},\{11\},\{12\}\}$

So: $\operatorname{pos}_{P 2}(D)=\operatorname{pos}_{C-\{\alpha 4\}}(D)=\bigcup_{\forall X \in U / \text { ind }(D)-} P_{2}(\mathrm{X})=U=\operatorname{pos}_{C}(D)$

Because:

$$
\begin{aligned}
& \operatorname{ind}\left(P_{2}-\left\{\alpha_{1}\right\}\right)=\{\{1\},\{2\},\{3,12\},\{4\},\{5\},\{6,9\},\{7\},\{8\},\{10\},\{11\}\} \\
& \operatorname{ind}\left(P_{2}-\left\{\alpha_{2}\right\}\right)=\{\{1,3,5\},\{2,8\},\{4\},\{6\},\{7,9\},\{8\},\{10\},\{11\},\{12\}\} \\
& \operatorname{ind}\left(P_{2}-\left\{\alpha_{3}\right\}\right)=\{\{1\},\{2\},\{3\},\{4\},\{5\},\{6,9\},\{7\},\{8,11\},\{10\},\{12\}\} \\
& \operatorname{ind}\left(P_{2}-\left\{\alpha_{5}\right\}\right)=\{\{1\},\{2\},\{3\},\{4\},\{5\},\{6\},\{7\},\{8\},\{9\},\{10,12\},\{11\}\}
\end{aligned}
$$

So: $\operatorname{pos}_{P 2-\{\alpha 1\}}(D)=\bigcup_{\forall X \in U / \text { ind }(D)} P_{2}-\left\{\alpha_{1}\right\}(\mathrm{X}) \neq \operatorname{pos}_{P 2}(D)$

So the attribute $\alpha_{1}$ is relative necessary to $\mathrm{D}$ in $P_{2}$.

$$
\operatorname{pos}_{P 2-\{\alpha 2\}}(D)=\bigcup_{\forall X \in U / \text { ind }(D)} P_{2}-\left\{\alpha_{2}\right\}(\mathrm{X}) \neq \operatorname{pos}_{P 2}(D)
$$

So the attribute $\alpha_{2}$ is relative necessary to $\mathrm{D}$ in $P_{2}$.

$$
\operatorname{pos}_{P 2-\{\alpha 3\}}(D)=\bigcup_{\forall X \in U / \text { ind }(D)} P_{2}-\left\{\alpha_{3}\right\}(\mathrm{X}) \neq \operatorname{pos}_{P 2}(D)
$$

So the attribute $\alpha_{3}$ is relative necessary to $\mathrm{D}$ in $P_{2}$.

$$
\operatorname{pos}_{P 2-\{\alpha 5\}}(D)=\bigcup_{\forall X \in U / \text { ind }(D)} P_{2}-\left\{\alpha_{5}\right\}(\mathrm{X}) \neq \operatorname{pos}_{P 2}(D)
$$

So the attribute $\alpha_{5}$ is relative necessary to $\mathrm{D}$ in $P_{2}$. It is known that $P_{2}$ is independent to $\mathrm{D}$.

In summary, attribute subfamily set $\mathrm{P}_{2}=\left\{\alpha_{1}, \alpha_{2}, \alpha_{3}, \alpha_{5}\right\}$ satisfies the definition of relative predilection, so it is one relative predilection of the decision-making table. In a similar way, $\mathrm{P}_{3}=\left\{\alpha_{1}, \alpha_{2}, \alpha_{3}, \alpha_{4}\right\}$ is not the relative predilection of the decision-making table. So all predilection of the decision-making table is $\operatorname{rec}_{C}(D)=\left\{\alpha_{1}, \alpha_{2}, \alpha_{3}, \alpha_{5}\right\}$. So the index "personnel diathesis" is deleted, the index "system survival" is remained. Therefore, the evaluation indexes are command and decision-making, network communication, information processing, system survival, which has achieved the optimization of the index system.

\section{The index system after predigested}

It is known by the above predilection result: the factors which influence the equipment support command effectiveness assessment are: command and decision-making, network communication, information processing, system survival. So the index system after predigested is as shown in the figure 2 . 


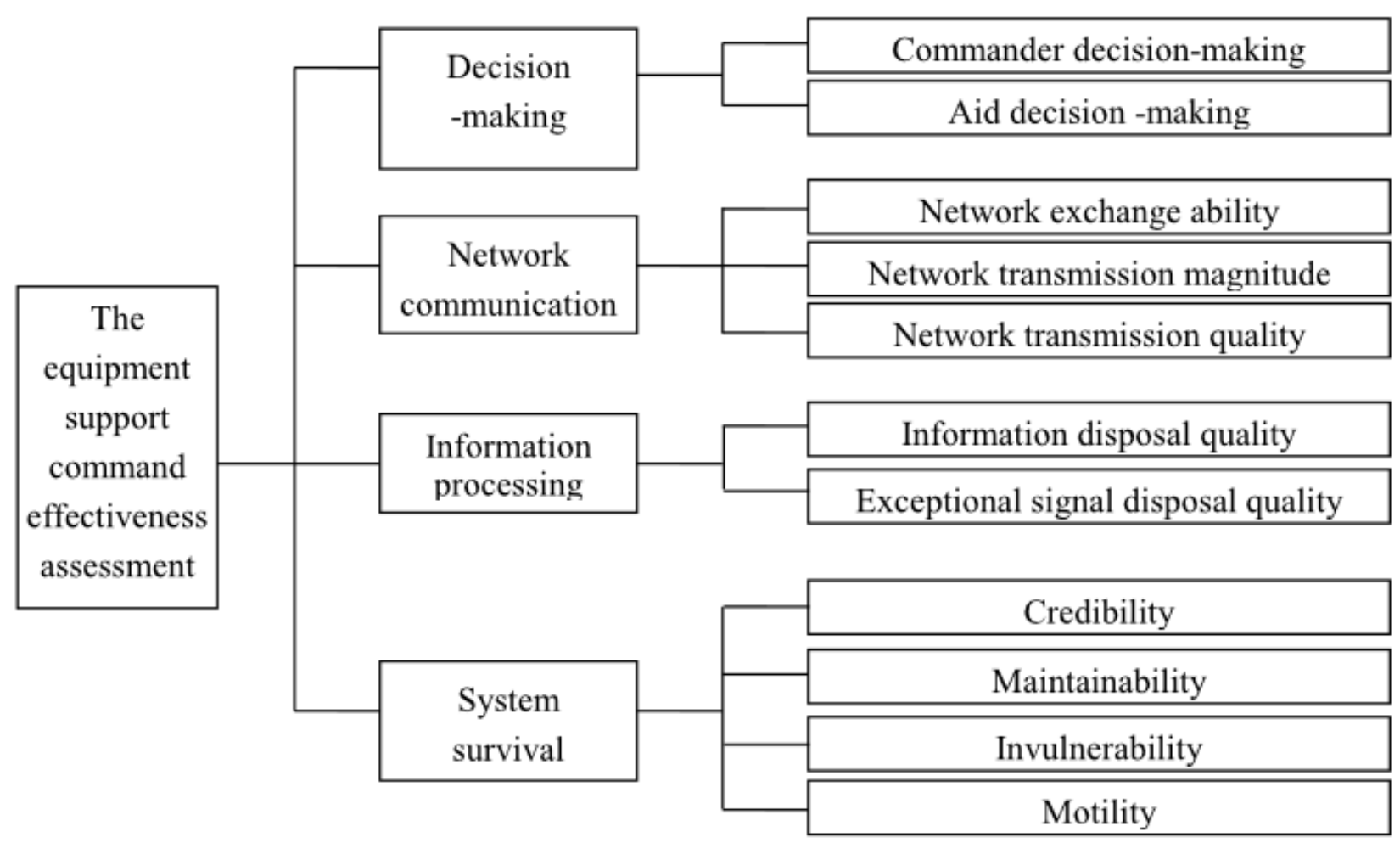

Figure 2 Index system of the equipment support command effectiveness assessment after predigested

\section{Conclusions}

The index system predilection methods of the equipment support command effectiveness assessment based on the rough set can eliminate the redundant information farthest and the reliant relationship of the indexes, on the premise of influencing the vital information. It has reduced the influence of subjective factors accordingly at the equipment support command effectiveness assessment, and improved the availability and objectivity of the assessment conclusions of the equipment support command effectiveness.

\section{Reference documentation}

[1] Pawlak Z. Rough Sets. International Journal of Computer and Information Science, 1982, 11(5): 341-356

[2] Pawlak Z. Rough Sets-theoretical Aspects of Reasoning about Data. Dordrecht: Kluwer Academic Publishers, 1991:35-46

[3] Miao Duoqian. Rough Sets-theory, arithmetic and application. Beijing: Publishing Company of Tsinghua University, 2008:174-180 